\title{
Antioxidants, its role in preventing free radicals and infectious diseases in human body
}

\author{
Muhammad Suleman ${ }^{1,2 *}$, Azmatullah Khan ${ }^{1,4}$, Abdul Baqi ${ }^{3,4}$, \\ Muhammad Sharif Kakar ${ }^{5}$, Samiullah ${ }^{3}$ and Muhammad Ayub ${ }^{1}$ \\ 1. Institute of Biochemistry, University of Balochistan, Quetta 87300-Pakistan \\ 2. Balochistan Residential College Loralai, Balochistan-Pakistan \\ 3. Department of Chemistry, University of Balochistan, Quetta 87300-Pakistan \\ 4. Colleges, Higher and Technical Education Department, Balochistan, Quetta-Pakistan \\ 5. Agriculture Research Institute, Sariab-Quetta, Balochistan-Pakistan \\ *Corresponding author's email: muhammadsuleman587@gmail.com \\ Citation
}

Muhammad Suleman, Azmatullah Khan, Abdul Baqi, Muhammad Sharif Kakar, Samiullah and Muhammad Ayub. Antioxidants, its role in preventing free radicals and infectious diseases in human body. Pure and Applied Biology. Vol. 8, Issue 1, pp380-388.http://dx.doi.org/10.19045/bspab.2018.700197

\begin{tabular}{llll}
\hline \hline Received: 14/09/2018 & Revised: 01/12/2018 & Accepted: 03/12/2018 & Online First: 03/12/2018 \\
\hline \hline
\end{tabular}

\section{Abstract}

Recent research on herbal field reports various ailments associated with free radicals. The risk of ailments because of oxidative stress increases due to undesirable way of life, exposure of natural and synthetic chemicals, cigarette smoking, medications, stress and so on. Cancer prevention agents are the substances which can search free radicals and help diminish the frequency of oxidative pressure induced harm. The main sources of antioxidants are vitamins, fruits, minerals, plants and vegetables. The functions of antioxidants are to neutralize the effect of reactive oxygen species (ROS) and prevent various diseases such as cancer, diabetes and cardiovascular diseases. The presence of antioxidants can be evaluated by various methods but the cheapest and easiest available methods are 1, 1-diphenyl-2-picrylhydrazyl (DPPH), total antioxidants capacity (TAC), total phenolic contents (TPC), reducing power (RP) and ferric reducing antioxidant potential (FRAP) methods. This review generally discusses the information related to the antioxidants and their role in changing the free radicals into neutral or less reactive species. It also discusses the role of antioxidant enrich sources in decreasing the risk of different human diseases.

Keywords: Antioxidants; Free radicals; Oxidation; Prevention; Species

\section{Introduction}

Antioxidant is a substance, present in small concentrations in body that helps in preventing the oxidation of substrate and plays a major role in the defense mechanism of body against reactive oxygen species [14]. It is reported that an antioxidant delays, inhibits or eliminates oxidative damage of targeted molecules. Antioxidants can prevent oxidation of substrates even at low concentration and perform various biological roles in an animal's body, while in plants, it functions as radical scavenger. Various types of antioxidants are found in nutritional sources such as fruits, spices, vegetables, herbs, tea etc. In animal body, they act as free radicals scavengers $[5,6]$. Antioxidants thus play a crucial role in the defense against free 
radical damages, which are detrimental for animal's physiology. Systematic uses of fruits and vegetables with anti-oxidative properties have been reported in the control of chronic diseases [7]. Diet rich in antioxidants has a far reaching health benefits in the long run $[8,9]$. One such example is the use of citrus fruits, which is rich in vitamin $\mathrm{C}$ and have large amount of natural antioxidants that have a number of physiological benefits. In addition, blueberries, grapes, strawberries, spinach, red beans etc. are known for their antioxidant properties and are recommended to be included in the diet $[10,11]$. In addition, fruits such as jackfruits are good sources of vitamins ( $\mathrm{C}, \mathrm{A})$ and phenolic components with antioxidant properties $[12,13]$. There are a large number of other fruits and vegetables that serve as source of various antioxidants.

\section{Various types of antioxidants}

There are various types of antioxidants: exogenous present in food are called dietary antioxidants, found in fruits are natural products, produced in the body are endogenous antioxidants and produced synthetically are synthetic antioxidants, play a significant role in maintaining animal physiology.

\section{Dietary antioxidants}

Dietary antioxidants are used to prevent the process of oxidation, chemical reaction promoted by reactive oxygen species such as oxygen peroxide, affecting the wellbeing of living organisms by free radicals. Antioxidants such as tocopherols, acrobats and carotenoids are well known examples of dietary antioxidants which play an important role in the treatment of chronic infections [14]. Amongst the other antioxidants are vitamins $(\mathrm{C}, \mathrm{E})$, carotene, $\beta$-carotene and carotenoids like lycopene and lutein [15]. In extracellular fluids, water-soluble antioxidant like vitamin $\mathrm{C}$ is considered to be the most important antioxidant. Considering the aqueous phase, it is suitable for neutralizing reactive oxygen species before the instigation of lipid peroxidation. Vitamin $E$ is one of the major lipid soluble antioxidant having a role in cell membrane repair by preventing oxidation of membrane lipids [16]. B-carotene protects fat-rich tissue by preventing their oxidation thus serving as an antioxidant and is known to function along with vitamin E [17]. Flavonoids antioxidants in plants protect them from different environmental pressures, whereas in animals, they act as anti-inflammatory, anti-viral, antiaging and anti-cancer agent [18-21].

\section{Synthetic antioxidant}

It is also an important type of antioxidant that is chemically manufactured and then added to the food as preservatives to inhibit fat oxidation [22]. These antioxidants are divided into two main groups based on their method of action: essential antioxidants and secondary antioxidants. The main antioxidants are more important which stop the creation of free radicals during oxidation. They consist of different types.

\section{Natural antioxidant}

Natural antioxidants are the innumerable ingredients of fruits and vegetables that have attracted much scientific attention [23, 24]. Natural antioxidants are created in all parts of plants and nutrients, because they live under continuous oxidation stress from free radicals and ROS. In this case, different tissues have produced antioxidant systems to manipulate free radicals, lipid oxidation catalysts, oxidation intermediates and secondary collapse yields [25-28]. These antioxidant mixtures consist of phenolic acids, carotenoids, tocopherols, flavonoids that can obstruct $\mathrm{Fe}^{+3}$ induced oxidation, clean free radicals and serve as metabolites [29, 30]. Spices and herbs are used in special foods for their flavor and in medicinal mixtures for their biological effects, which often involve large concentrations of phenolic compounds with strong hydrogen activity [31, 32]. 
Natural sources like fruits, vegetables and meats are noted to have all antioxidants. There are many natural antioxidants common to daily foods such as mostly vitamin A (carotenoids), vitamin E (tocopherol), vitamin $\mathrm{C}$ (ascorbic acid) various polyphenols including flavonoids, lycopene of carotenoids), anthocyanins and coenzyme Q 10 , recognized as Ubiquitin, a form of protein.

\section{Endogenous antioxidants}

Along with nutritional antioxidants, the health depends on many self-defense mechanisms for defense against the destruction of cells caused by free radicals. The antioxidant enzymes SOD, catalase, peroxidase and glutathione act on the metabolism of poisonous intermediates and need micronutrients like $\mathrm{Fe}, \mathrm{Se}, \mathrm{Zn}, \mathrm{Cu}$ and Mn to obtain the best catalyst activity. It has been recommended that adequate dietary intake of these rare metals may control the efficacy of these mechanisms to protect antioxidants [33]. Glutathione, an antioxidant soluble in water which is produced from glycine, glutamate and cysteine amino acids, reduces the types of reactive oxygen like lipid peroxides and also plays a main role in the biological metabolism. Liver when exposed to foreign matter leads to oxidation reactions via the higher regulation of purification enzymes, i.e. and the various cytochromes P450 with oxidase function. As long as any organism confronts exceptional levels of alien organisms, additional glutathione is used for conjugation (a major phase in detoxification), making it less helpful as an antioxidant. It is suggested through research that glutathione and ascorbic acid (Vit-C) work collectively to reduce free radicals and need to have a precise effect on each other [17]. Lipoic acid, another important internal antioxidant which is classified as thiol or pythol, is a sulfur particle known to be involved in the reaction that stimulates the removal of oxidized carboxylic of alpha-keta acids, such as pyruvate and alphaketoglutarate, in the Krebs cycle. Lipoic acid may also be used as an antioxidant resulted by mixing with the mass of the congestion. Research also stated that Lipoic acid has little consequence on other antioxidants [34].

\section{Exogenous Antioxidants}

A type of antioxidant that can be derived from natural bases such as vitamins (flavonoids, anthocyanins, some mineral compounds) as well as synthetic compounds, such as butyl hydroxyanisol, butyl hydroxy, tuline, galate, etc [35]. There is an increasing interest in antioxidants, especially in those that aim to prevent the toxic effects recognized by free radicals in the human body as well as the degradation of fat and other nutrient components [36].

\section{Source of Antioxidants}

The main sources of antioxidants are vegetables, fruits, fruit juices, peroxidase, polyphenols, vitamins, amino acids, minerals and many enzymes are the basic sources of antioxidants, but fruit and vegetable juices, beverages and hot drinks contain large amounts of antioxidants, vitamin $\mathrm{C}$, alphacarotene, Maylard reaction products, vitamin $\mathrm{E}$ and lycopene [37]. It has been found that drinking fruit juices, drinks and hot drinks reduce diseases and deaths caused by degenerative diseases [38-42]. The trends in epidemiological studies are that fever fruits, vegetables and processed foods ensure greater safety against the growth of ailments produced by oxidative stress like type 2 diabetes, obesity, cancer, cardiovascular disease and cataract due to high blood pressure. The reason for their health- building effect is the presence of prominent antioxidants [43].

\section{Function of antioxidants}

The FDA (Food and Drug Administration) describes antioxidants as food compounds that are used with food for diseases prevention [44]. 
Antioxidants play an important role in the preventive inspiration practiced by plant foods [45-47]. Recognize that regular consumption of vegetables and fruits reduces the risk of long-term illness [48]. Studies have found that a rich antioxidant diet has a very positive long-term health effect [49]. Recently, it has been found that antioxidants play vital role in decreasing radicalism, oxidative stress, cancer prevention, heart disease and longevity [50]. All antioxidants act as a team player, and an antioxidant system is responsible for preventing the devastating effects of free radicals, as well as toxic products from their breakdown. However, the primary role of antioxidants is to control the amount of free-radical formation in a mirror system where the deficiency of a component affects the effectiveness of others [51]. The main function of antioxidants is to reduce the amount of oxidation of body fat and oils. The fourth method is to add the fat to the antioxidants. This method is the composition of a compound or compound between the fat and the antioxidants. Among the food ingredients that fight against prolonged diseases, much attention has been paid to phytochemicals, and plant-derived molecules are capable with intact antioxidant power. The cumulative and synergistic activities of biologically active molecules found in plant foods are responsible for their antioxidant properties.

\section{Function of vitamin $\mathbf{C}$}

The protective functions or productive effect of vitamin $\mathrm{C}$ is the treatment of various types of cancer such as lungs, breast, oral cavity, pancreas, rectum and stomach [51]. In difficult circumstances, the adrenal glands respond by secreting the hormones that start or activate the "fight or escape" reaction. It has been determined that $200 \mathrm{mg}$ of vitamin $\mathrm{C}$ a day may reduce the amount of stress hormones. Stress destroys the immune system. Heavy doses of vitamin $\mathrm{C}$ improve the number of antibodies that fight germs as well as bugs in restrained and resting mice, while increasing the number of antibodies that are innumerable in uncompressed mice [52].

\section{Vitamin E}

Vitamin E, a fat soluble vitamin, is one of the most important antioxidants $[53,54]$. The main role of tocopherol as an antioxidant is to break the chain of free radical. Resultantly, the phenolic $\mathrm{H}$ atom is transferred to a peroxyl fatty atom converting it into lipid hydrogen peroxide and vitamin $\mathrm{E}$ radical [55]. Vitamin $\mathrm{E}$ is the most powerful antioxidant that recommends oxidative stability to red palm olein (RPO) and also helps to retain the carotenoids and other parameters of excellence to authenticate the quality of oil [56]. Vitamin $\mathrm{E}$ penetrates radical intermediates peroxide in fatty peroxides and it is responsible for protecting polyunsaturated fatty acids (PUFA) in the cell membrane and Low Density Lipoprotein (LDL) against phospholipid peroxidation. Vitamin E is recommended for a variety of purposes from aging delay to healing of sunburn. The different functions that maintain the normal state of cells and provide their physical form of skin and tissues protect red blood cells (RBC,s) and augment immunity. Significant sources of tocopherol (vitamin E) consist of green leafy vegetables, wheat germ and seeds whole grains vegetable oil and fish liver oil.

\section{Beta-carotene}

It has a powerful antioxidant property used to neutralize free radicals as well as reactive oxygen molecules actually responsible for harmful grease in cell membranes as well as genetic material, which can lead to cardiovascular disease and cancer [57]. Till now, the constructive properties of betacarotene and other carotenoids in humans were not decided to be the consequence of their antioxidant potential. The importance of it for human health is the deactivation of 
ROS, preventing diseases like cancer and cardiovascular disease, is not obvious. Studies in the laboratory show that carotenoids may also inhibit fat oxidation in certain cases. Additionally, antiatherosclerosis property may be present in beta carotene however, they seem to be more complex in the human body [58].

\section{Selenium}

Selenium, a main element, plays high role in curing human beings through its antioxidant potential. Certainly, it is a specific ingredient needed in the formation and function of approximately 20-40 enzymes, most of which support to stop cellular harm from natural by products to the process of oxygen metabolism, called reactive oxygen species (ROS) and free radicals [59, 60]. The systematic role of the immune system needs selenium which also have antiviral properties $[61,62]$. Special influences on inflammatory actions are among other important events known for selenoproteins [63].

\section{Polyphenol antioxidant}

Recent evidences strongly support the contribution of polyphenols in the prevention of cardiovascular diseases, cancers and also suggest a key role in the prevention of degenerative neuropathies as well as diabetes [64]. An important development has been made in the field of heart disease, and it is now proven that some polyphenols, administered as enhancements or with food, improve health conditions, as evidenced by the number of vital markers closely associated with cardiovascular risk $[65,66]$. Epidemiology tends to confirm the defensive effects of polyphenols against cardiovascular disease.

\section{Glutathione}

Glutathione is said to protect cells from toxic substances like free radicals. The glutathione produced in human body is due to three important amino acids like cysteine, glycerin and glutamic acid. The various food sources consist of large quantities of naturally occurring glutathione from asparagus, squash, grapefruit, potatoes, melons, plums, squash, spinach, cauliflower, etc. Spices, meat and foods that produce sulfur containing amino acids (such as eggs) are the ideal sources for upholding and enhancing vital levels of glutathione [67].

\section{Peroxidase}

A type of enzyme found particularly in herbs as well as in leukocytes that contain complex protein with hematinic groups which can stimulate oxidation of several constituents. The main sources of peroxidase consist of radish root, soybean, turnip, fruit and mango fruit $[68]$.

\section{Flavonoids}

Flavonoids help in activating the potential of antioxidants. Furthermore, they also assist in cellular health and proper growth all over the body. It also works with vitamin $\mathrm{C}$ in order to reduce oxidative stress and especially the water part of the cell and can also reduce certain effects of aging. The number of unique flavonoids over 4000 can be more effective when using multiple types together. The main food sources are cranberries, cabbage, beet, black and red grapes, oranges, berries, grapefruit, lemon and green tea [69].

\section{Conclusion}

Antioxidants play a crucial role in the defense system of living organisms against free radical impairment and sustaining optimal health. Systematic utilization of fruits and vegetables with antioxidant properties have been identified in reducing diseases in longterm and rich antioxidant diet has a very longterm healthy effect. Thus, fruits and vegetables are the best natural source of antioxidants needed for the wellbeing of human life by reducing free radicals. Daily consumption of these fruits and vegetables in sufficient quantities ensures protection against a number of illnesses such as cancer, heart disease, obesity, kidney disease, stress, high blood pressure, type 2 diabetes, aging, anti-allergic and viral infections. 


\section{Authors' contributions}

Conceived the idea: M Suleman \& M Ayub, Proof reading: A Khan, A Baqi, MS Kakar \& Samiullah, Wrote the paper: M Suleman, Corrections: A Khan, A. Baqi \& Samiullah, Corresponding author: M Suleman.

\section{References}

1. Ou B, Dejian H, Maureen AF \& Elizabeth KD (2002). Analysis of antioxidant activities of common vegetables employing oxygen radical Absorbance Capacity (ORAC) and Ferric Reducing Antioxidant Power (FRAP) Assays: A comparative study. J Agric Food Chem 50(11): 3122-8.

2. Vivek KG \& Surendra KS (2006). Plants as natural antioxidants. Natural Production Radia 5(4): 32-334.

3. Halliwell B \& Gutteridge JMC (1995) The definition and measurement of antioxidants in biological systems. Free Radical Biology and Medicina 18(1): 125-6

4. Flora S J S (2007). Role of free radicals and antioxidants in health and disease. Cellular and Mol Biol 53(1): 12.

5. Rajesh N K, Satish Y \& Mundal S (2009). Antioxidant: A review. J Chemical and Pharma Res 1: 102-104.

6. Taira J, Tsuchida E, Katoh M C, Uehara M \& Ogi T (2015). Antioxidant capacity of betacyanins as radical scavengers for peroxyl radical and nitric oxide. Food Chem 166: 531-536.

7. Dembinska-Kiec A, Mykkanen O, KiecWilk B \& Mykkanene H (2008). Antioxidant phyto-chemicals against type 2 diabetes. British J Nutri 99: 109117.

8. Sin HPY, Liu DTL \& Lam DSC (2013). Life style modification, nutritional and vitamins supplements for age-related macular degeneration. Acta Ophthalmol 91: 6-11.
9. Willis LM, Shukitt-Hale B \& Joseph JA (2009). Recent advances in berry supplementation and age-related cognitive decline. Curr Opinion in Clin Nutrition and Metabolic Care 12: 91-94.

10. Scalbert A, Johnson IT \& Saltmarsh M (2005). Polyphenols: antioxidants and beyond. The American $J$ of Clinical Nutrition 81(1): 215S-217S.

11. Netzel M, Netzel G, Tian Q, Schwartz S \& Konczak I (2007). Native Australian fruits: a novel source of antioxidants for food. Innovative Food Sci \& Emerging Technol 8(3): 339-346.

12. Swami SB, Thakor NJ, Haldankar PM \& Kalse SB (2012). Jackfruit and its many functional components as related to human health: A Review. Comprehen Rev in Food Sci and Food Safety 11: 565576.

13. Pereira MC, Steffens RS, Jablonski A, Hertz PF, Rios AD \& Vizzotto M (2013). Characterization, Bioactive Compounds and Antioxidant Potential of Three Brazilian Fruits. J Food Compos and Analysis 29: 19-24.

14. Gomes FS, Costa PA, Campos MBD, Tonon RV, Couri S \& Cabral LMC (2013). Watermelon Juice Pre- treatment with Microfiltration Process for Obtaining Ly- copene. Intern J of Food Sci and Technol 48: 601-608.

15. Boskou D, Blekas G \& Tsimidou M (2005). Phenolic compounds in olive and olives. Current Topics in Nutraceutical Res 3: 125-136.

16. Gupta V K, Shrivastava RK, \& Singh N (2018). Status of exogenous antioxidant, total antioxidant capacity and oxidative stress in sca patients. Indian $J$ of Applied Res 8(8).

17. Kim H Y, Kim H, Chun J \& Chung H (2017). Changes in beta-carotene, vitamin $\mathrm{E}$, and folate compositions and retention rates of pepper and paprika by color and cooking method. $J$ of the 
Korean Soc of Food Sci and Nutrition 2(3): 74-80.

18. Wang T Y, Li Q \& Bi K S (2018). Bioactive flavonoids in medicinal plants: Structure, activity and biological fate. Asian J of Pharma Sci 13(1): 12-23.

19. Kuhnau J (2010). The flavonoids: A class of semi-essential food components: their role in human nutrition. World Rev Nutrition Diet 24: 117-91.

20. Havsteen B (2009). Flavonoids, a Class of Natural Products of High Pharmacological Potency. Biochem Pharm 32: 1141-1148.

21. Li Y, Pham V, Bui M, Song L, Wu C, Walia A \& Zi X (2017). Rhodiola rosea L.: an herb with anti-stress, anti-aging and immunostimulating properties for cancer chemoprevention. Curr Pharmacol Rep 3(6): 384-395.

22. Pateiro M, Barba FJ, Domínguez R, Sant'Ana AS, Khaneghah AM, Gavahian M \& Lorenzo J M (2018). Essential oils as natural additives to prevent oxidation reactions in meat and meat products: A review. Food Res Intern 113:156-166.

23. Yadav \& Chen Z (2008). Research of anti-oxidative capacity in essential oils of plants. China Conditions 11: 40-43.

24. Diwani El, Rafie G \& Hawash S (2009). Protection of biodiesel and oil from degradation by natural antioxidants of Egyptian Jatropha. Intern J Environ Sci Technol 6: 369-378.

25. Nakatani N (2003). Biologically functional constituents of spices and herbs. J. of Japan Soc Nutrition Food Sci 56: 389-395.

26. Agati G, Matteini P, Goti, A \& Tatting M (2007). Chloroplast located flavonoids can scavenge singlet oxygen. New Phytol 174: 77-81.

27. Brown JE \& Kelly MF (2007). Inhibition of lipid peroxidation by anthocyanins, anthocyanidins and their phenolic degradation products. European J Lipid Sci and Technol 109: 66-71.

28. Iacopini P, Baldi M, Storchi P \& Sebastiani L (2008). Catechin, epicatechin, quercetin, rutin, and resveratrol in red grapes: content, in vitro antioxidant activity and interactions. $J$ Food Comp Anal 21: 589-598.

29. Khanduja KL (2003). Stable free radical scavenging and anti per oxidative properties of resveratrol in vitro compared with some other bio flavonoids. Indian $J$ Biochem and Biophysics 40: 416-422.

30. Ozsy N, Candoken E \& Akev N (2009). Implications for degenerative disorders: anti oxidative activity, total phenols, flavonoids, ascorbic acid, beta-carotene and beta-tocopherol in Aloe vera. Oxid Medicine Cell Long 2: 99-106.

31. Zhang H \& Tsao R (2016). Dietary polyphenols, oxidative stress and antioxidant and anti-inflammatory effects. Curr Opinion in Food Sci 8: 3342.

32. Muchuweti M, Kativu E, Mupure $\mathrm{CH}$, Chidewe C, Ndhlala AR \& Benhura MAN(2007). Phenolic composition and antioxidant properties of some spices. American J Food Technol 2: 414-420.

33. Nimse SB \& Pal D (2015). Free radicals, natural antioxidants, and their reaction mechanisms. Rsc Adv 5(35): 2798628006.

34. Kagen VE (2001). Dihydrolipoic Acid-A universal antioxidant both in the membrane and in the aqueous phase. Biochemical Pharmacology 44: 16371647.

35. Litescu SC (2011). Biosensors applications on assessment of reactive oxygen species and antioxidants. Environ Biosensors 1: 35-40.

36. Molyneux P (2004). The use of the stable free radical diphenylpicrylhydrazyl 
(DPPH) for estimating antioxidant activity. $J$ Sci and Technol 26: 211-219.

37. Ramadan-Hassanien MF (2008). Total antioxidant potential of juices, beverages and hot drinks consumed in Egypt screened by DPPH in vitro assay. Grasas Yaceites 59: 254-259.

38. Ashurst PR (2016). Chemistry and technology of soft drinks and fruit juices. $3^{\text {rd }}$. USA.John Wiley \& Sons.

39. Rimm EB, Aschiero A, Giovannucci E, Spiegelman D \& Stampfer MJ (2005). Vegetable, fruits and cereal fiber intake and risk of coronary heart disease among men. J American Med Assoc 275: 447451.

40. Cohen JH, Kristal AR \& Stanford JL (2000). Fruit and vegetable intakes and prostate cancer risk. J Natural Cancer Institute 92: 61-68.

41. La Vecchia C, Altieri A \& Tavani A (2001). Vegetables, fruit, antioxidants and cancer: A review of Italian studies. European J Clinical Nutri 40: 261-267.

42. Rodríguez-Bernaldo de Quirós A \& Costa HS (2006). Analysis of carotenoids in vegetable and plasma samples- A Review. J Food Compos Anal 19: 97111.

43. Halvorsen BL, Holte K, Myhrstad MCW, Barikmo I \& Hvattum E (2002). A systematic screening of total antioxidants in dietary plants. J Nutrition 132: 461471.

44. Ohlsson $\mathrm{T} \&$ Bengtsson N (2002). Minimal processing technologies in food industry. $\quad 2^{\text {nd }}, \quad$ USA, Woodhead Publishing.

45. Yadav A, Kumari R, Yadav A, Mishra J P, Srivatva S \& Prabha S (2016). Antioxidants and its functions in human body: A review. Res Environ Life Sci 9(11): 1328-1331.

46. Willett WC (2011). Micro-nutrients and cancer risk. J of the American Med Assoc 53: 265-269.
47. Liyana-Pathirana CM, Shahidi F \& Alasalvar C (2006). Antioxidant activity of cherry laurel fruit (Laurocerasus officinalis Roem.) and its concentrated juice. Food Chem 99: 121-128.

48. Kalcher K, Svancara I, Buzuk M, Vytras K \& Walcarius A (2009). Electrochemical sensors and biosensors based on heterogeneous carbon materials. Monatsh Chem 140: 861-889.

49. Peter FS (2007). Natural antioxidants in poultry nutrition: New developments. 16th European Symposium on Poultry Nutrition 669-676.

50. Hajian S (2015). Positive effect of antioxidants on immune system. Immunopathol Persa 1(1) 2015.

51. Simon JA, Hudes ES \& Tice JA (2001). Relation of Serum Ascorbic Acid to Mortality among Adults. J American Col Nutrition 20: 255-263.

52. Janda K, Kasprzak M \& Wolska J (2015). Vitamin C-structure, properties, occurrence and functions. Pomeranian $J$ of Life Sci 61(4): 419-425.

53. Handan MK, Suleyman M \& Yeter D (2007). Vitamin status in yearling rams with growth failure. Turkey $J$ Veterinary Animal Sci 31: 407-409.

54. Paul WS \& Sumit S (2002). Antioxidants in dietary oils. Their potential role in breast cancer prevention. Mal J Nutrition 8: 1-11.

55. Abdalla AE (2009). The role of antioxidant (Vitamin E) in the control of lead pollution and enhancement of growth within nile tilapia (Oreochromis niloticus). Intern $J$ Applied Res. Veterinary Medical 3: 97-101.

56. Bashir MR, Guido MH, Wim JFV \& Aalt B (2004). The extraordinary antioxidant activity of vitamin E phosphate. Bioch Biophy Acta 1683: 16-21.

57. Holick CN, Michaud DS, StolzenbergSolomon R, Mayne ST, Pietinen P, Taylor PR \& Albanes D (2002). Dietary 
carotenoids, serum $\beta$-carotene, and retinol and risk of lung cancer in the alpha-tocopherol, beta-carotene cohort study. American J of Epidemiol 156(6): 536-547.

58. Young AJ \& Low GM (2001). Antioxidant and pro-oxidant properties of carotenoids. Arch Biochem and Biophy 385: 20-27.

59. Hawkes WC \& Alkan Z (2010). Regulation of redox signaling by seleno proteins. Biol Trace Element Res 134: 235-51.

60. Higuchi A, Takahashi K, Hirashima M, Kawakita T \& Tsubota K (2010). Solano protein $\mathrm{P}$ controls oxidative stress in cornea 5: 9911.

61. Wójtowicz H, Kloc K, Maliszewska I, Młochowski J, Piętka M \& Piasecki E (2004). Azaanalogues of ebselen as antimicrobial and antiviral agents: synthesis and properties. Il Farmaco 59(11): 863-868.

62. Huang Z, Rose AH \& Hoffmann PR (2012). The role of selenium in inflammation and immunity: from molecular mechanisms to therapeutic opportunities. Antioxidants \& Redox Signaling 16(7): 705-743.

63. Curran JE, Jowett JB, Elliott KS, Gao Y, Gluschenko K, Wang J, Abel Azim DM, Cai G, Mahaney MC, Comuzzie AG,
Dyer TD, Walder KR, Zimmet $\mathrm{P}$, MacCluer JW, Collier GR \& Blangero $\mathrm{J}(2005)$. Genetic variation in selenoprotein S influences inflammatory response. Nat Genetic 37: 1234-41.

64. Scalbert A, Manach C, Morden C, Remesy C \& Jimenez L (2005). Dietary poly phenols and prevention of diseases. Critical Rev of Food Sci Nutri 45: 287306.

65. Vita JA (2005). Polyphenols and cardiovascular disease: effects on endothelial and platelet function. American J Clinical Nutrition 81: 292307.

66. Arts ICW \& Hollman PCH (2005). Polyphenols and disease risk in epidemiologic studies. American $J$ Clinical Nutrition 81: 317-325.

67. Ashadevi DS \& Gotmare SR (2015). The health benefits and risk of antioxidants. Pharmacophore 6: 25-30.

68. Sunil K (2014). The importance of antioxidant and their role in pharmaceutical science: A Review. Asian J of Res in Chem and Pharmac Sci 1: 2744.

69. Kozlowska A \& Szostak-Wegierek D (2014). Flavonoids-food sources and health benefits. Roczniki Państwowego Zakładu Higieny 65(2): 79-85. 